Law in the Digital Age. 2021. Vol. 2, no. 3.

Вопросы права в цифровую эпоху. 2021. Т. 2. № 3.

Research article

УДК 342.951

DOI: $10.17323 / 2713-2749.2021 .3 .98 .125$

\title{
Integrated Healthcare Delivery and Telemedicine: Existing Legal Impediments in India
}

\section{目 Dr. Chhavi Sharma1,}

\section{Dr. Reeta Sony²,}

\section{Dr. Meera Mathew ${ }^{3}$}

${ }^{1}$ Indian Institute of Public Administration, New Delhi, India, chhavi.mail1@gmail. com1,

${ }^{2}$ Centre for Studies in Science Policy, School of Social Sciences, Jawaharlal Nehru University, New Delhi, India, reetasony@mail.jnu.ac.in

${ }^{3}$ Symbiosis Law School, Noida, India ,meera@symlaw.edu.in

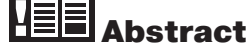

Technological innovation and development in the healthcare sector have cast the foundations for the growth of telemedicine. Telemedicine uses remote virtual channels to deliver healthcare services to regions in the rural and urban belts. The advantages of telemedicine include timely access to healthcare: in many cases, it would be difficult to provide timely healthcare services in the absence of telemedicine. In remote healthcare, telemedicine has been especially helpful in areas with scarce healthcare services. Telemedicine is not an autonomous service; rather, it is subject to different regulations of a complex ethical and medico-legal nature. The Constitution of India states that healthcare services are largely the responsibility of state governments as per item 6 "Public health and sanitation; hospitals and dispensaries" of the State List under Schedule 7 of the Constitution. However, the central government provides the framework for health policy and planning. In particular, the Ministry of Health and Family Welfare of India (MoHFW) is responsible for initiating the digitization of healthcare. In January 2020, the NDHB promulgated the comprehensive architectural framework of the "Federated National Health Information System." This framework is directed towards linking public and private healthcare organizations across all the value chains of primary, secondary and tertiary healthcare. Furthermore, on $25^{\text {th }}$ March 2020 after the unexpected 
outbreak of the COVID-19 pandemic, the Medical Council of India and the NITI Aayog released new telemedicine guidelines for registered medical practitioners to facilitate healthcare services during the complete lockdown. These guidelines set down the rules for providing medical consultations to patients using telemedicine in such areas as diagnosis, treatment and the avoidance of illness and injuries. They also govern research, evaluation and the continuing education of healthcare personnel. These guidelines have led to the empowerment of medical practitioners, yet they have also imposed various restrictions. In India, telemedicine is a nebulous concept that needs to be analyzed in the light of its prospective opportunities. This paper critically examines existing Indian collaborative approaches to digital health, the prevailing legal and ethical frameworks, and the correspondence of clinical practices to current medical guidelines. It further analyzes the steps taken by India to develop telemedical practices while balancing privacy norms, medico-legal responsibility and regulatory standards. To this end, we analyze the timeline of the development of telemedicine as well as examining the role of different policies in facilitating the promotion of telemedicine and the critical impact of technological innovation on the delivery of healthcare in rural and urban India.

\section{O-1国 Keywords}

virtual healthcare, telemedicine, ethics, legal implications, privacy, patients' rights

For citation: Sharma C., Sony R., Matthew M. Integrated Healthcare Delivery and Telemedicine: Existing Legal Impediments in India. Legal Issues in the Digital Age. 2021, no. 4, pp. 98-125. DOI: 10.17323/2713-2749.2021.3.98.125

\section{Introduction}

As healthcare institutions grow larger and merge, healthcare services become less affected by topography, remoteness, number of patients or even institutional limitations. Thanks to technological progress, digital healthcare or e-governance in healthcare is a bourgeoning sector. Visible progress in this area includes the accessibility of health information via web sites, on-line customer support, computerized and automated analysis, collaborative health improvement programs and electronic mail exchange with medical service providers. This electronically integrated healthcare system (though often termed "e-health") is based on technological innovations in telecommunications, audial/graphic technologies and computing that affect different domains from the provision of medical information to

1 "E-health is a broader term understood as juncture of therapeutic informatics, public health and trade, referring to healthcare services and information distributed or improved through the Internet and associated technologies." (WHO on e-Health in WHA58.28 Resolution passed at the Fifty-eighth World Health Assembly, Geneva, Switzerland, 2005) 
diagnosis and treatment [Della Mea V., 2001: 1-2]. Globally, the segment of healthcare is experiencing a paradigm shift in the mode of delivery and applications of healthcare services. Healthcare has lost its restrictive sense and come to mean the overall improvement of the human being; hence, it no longer refers to an act intended to restore a lost condition. When it comes to India, the healthcare industry has not made use of the Internet as profusely as other sectors so far. The Indian healthcare system has largely conventional stakeholders who believe in one-on-one consultations and diagnosis [Lahariya C. et al., 2007: 1-7].

It is owing to the pandemic and especially to the adoption of the new telemedicine guidelines that people have begun to go for digital check-ups and diagnosis. The application of digital tools, electronic commerce and technologies in every industry is driven by consumer welfare. From this standpoint, integrated healthcare is designed as a potential goal, an area of imminent significance, that legitimizes the use of enhancement practices. The electronic form of healthcare should enable the competent transfer

7. Physician starts

the assessment, diagnosis,

and treatment of patient

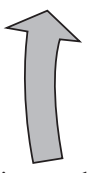

6. Patient and physician join the consultation based on the meeting ID at the appointed time

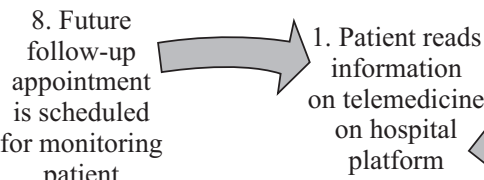

Telemedicine Process Cycle

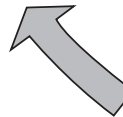

5. Data and time

of reservation is confirmed

by the attending medical staff and sent to patient

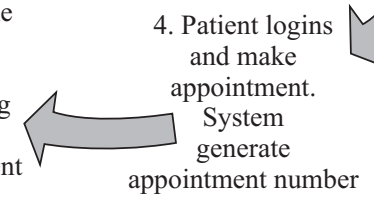

Figure 1. Telemedicine Flowchart

Source: Bokolo A. Jr. (2020) Use of telemedicine and virtual care for remote treatment in response to COVID-19 pandemic. J Med Syst, vol. 44, p. 132. 
of healthcare services to rural and inaccessible communities and generate cost benefit transactions. In India, telemedicine is a nebulous concept that needs to be analyzed in the light of the opportunities it offers. This paper critically examines the existing Indian (national and state) collaborative approaches to digital health, the prevailing legal and ethical frameworks, and the clinical practices corresponding to current medical guidelines to determine the need for reforms or new standards. It further analyzes how India has improved telemedical practices by balancing privacy norms, medico-legal responsibility and regulatory standards.

\section{Right to health and healthcare}

The word "health" has many different meanings. Among these, the "right to health" encompasses all the socio-economic, ecological and legal issues that have a direct relation to health. It includes the right to healthcare, which involves safeguarding access to appropriate and affordable healthcare and, in particular, to necessary diagnostics and essential treatment. ${ }^{2}$ The Constitution of India mostly places the responsibility for healthcare services on state governments. ${ }^{3}$ However, the health policy and planning framework is provided by the central government. ${ }^{4}$ The right to health is not explicitly expressed as a fundamental right in the Indian Constitution. In a broad interpretation that widens the scope of Article 21 by reading it together with the Fundamental Duties and Directive Principles, the Supreme Court has often interpreted the constitutional right to healthcare as a significant right. In Paschim Danga Khet Mazdoor Samity \& Ors v. State of West Bengal, 5the Supreme Court interpreted the state's obligation to provide qualitative healthcare in the context of the welfare state, widening the scope of Article 21 and the government's obligation to provide medical support to every person in the country. Furthermore, in Consumer Education and Research Centre \& Ors v. Union of

${ }^{2}$ See WHO Eleventh General Programme of Work (2006-2015). This report provides a global health agenda for WHO Member States, focusing on the elements of availability, accessibility, acceptability and quality ("AAAQ").

${ }^{3}$ See items 6 "Public health and sanitation; hospitals and dispensaries" and 9 "Relief of the disabled and unemployable" on the State List under Schedule 7 of the Constitution.

${ }_{4}$ The union government using its federal powers bears the primary responsibility for respecting international obligations. The constitutional responsibility for assuring the right to health, legislation on public health, and the responsibility to assure human rights are principally upon the union legislature. See Kothari J. Social rights and the Indian constitution. 2004. 6 SCC J-31.

${ }^{5}$ (1981). 1 SCC 246 
India, ${ }^{6}$ the Supreme Court stated that the right to health and medical care is a fundamental right of citizens under Article 21, read with Articles 39 (e), 41, 43, and 48-A of the Indian Constitution. In Paschim Banga Khet Mazdoor Samity \& Ors v. State of West Bengal \& Anr, the Court addressed the matter of the suitability and obtainability of emergency health treatment and upheld that the state bears the brunt of the responsibility for assuring that primary health centers are equipped to deliver instantaneous stabilizing treatment for grave injuries and tragedies. In other judgments, ${ }^{7}$ the Court indirectly confirmed the state's obligation to maintain standards.

Nevertheless, healthcare safeguards in India, unlike in other developed nations, are based on "supply-induced demand" that is need-based rather than "right-based." The right-based approach calls for a clear and transparent accountability mechanism in the state's decision-making, review and renovation of healthcare. It must be kept in mind that, when the affordability of treatment or medicine increases, leading to a shortage of medical practitioners, the only possible solution in the healthcare system is to rely upon technological progress. Any such transition must be effectuated by weakening the strictness of existing regulations and ignoring the conventional cultural mind-set while assuring people's rights in the process [McSherry R., Pearce P. et al., 2011: 182]. This right-based approach to technological progress in the health sector can be employed to control societal and demographic rigidities, reduce unfairness and health uncertainty, expand training, and reinforce public health scrutiny with the assistance of healthcare stakeholders for laying the foundation of public health capacity. In a speech of December 2017 UN Secretary-General Antonio Guterres stated that health is a right for all and in a new development era must have more streamlined and sustainable financing. ${ }^{8}$

Although Indian laws governing the healthcare industry are yet to be applied to e-health, it was necessary to promote health in a digital manner during the lockdown following the outbreak of the Covid-19 pandemic. A major step was to introduce a legal framework for telemedicine. ${ }^{9}$

${ }^{6}$ (1995). 3 SCC 42.

7 Vincent Panikurlangara v. Union of India. (1987). 2 SCC 165. Mahendra Pratap Singh v. State of Orissa. (1997). AIR (Ori) 37. Murli Deora v. Union of India and Ors. (2001). 8 SCC 765. Rakesh Chandra Narayan v. State of Bihar (1989). SCC Supl. (1) 644 in healthcare services with due attention to international treaties and documents.

${ }^{8}$ Available at: https://www.un.org/sg/en/content/sg/speeches/2017-12-14/universalhealth-coverage-forum- remarks (accessed: 02.11.2020)

9 There is a difference between telehealth and telemedicine. While telemedicine has a clinical aspect, telehealth is any use of information technology for health purposes. Al- 
India lacks healthcare manpower and infrastructure, which prevents it from dealing with pressures and medicinal demands. The shortage of manpower in the public healthcare system is currently estimated at 6 hundred thousand doctors, 4 hundred thousand dental surgeons and 10 hundred thousand nursing staff [Sharma A. et al. 2013: 112-117]; [Mishra S.K., Kapoor L., Singh I.P. 2009: 568-575]. The distribution of healthcare services is also skewed. This can be attributed to the fact that approximately $75 \%$ of the healthcare infrastructure and manpower is based in urban areas where only $27 \%$ of the total population resides. The difference in the distribution of resources between rural and urban areas can be inferred from the fact that the number of doctors per 1,000 population is 0.39 in the countryside in comparison to as much as 1.33 in cities, resulting in a national average of 0.69 [Bagchi S., 2006: 82].

Such an improper distribution of healthcare resources in rural and urban settings can be corrected through telemedicine. Telemedicine can be viewed as the fastest, most effective and least expensive method of reducing this discrepancy [Achary R.V., Rai J.J., 2016: 5]. In [Achary R.V., Rai J.J., 2016: 5], the author argues that the most prominent and important advantage of telemedicine is its ability to reach rural areas of the country. Further, telemedicine possesses the potential to provide high-quality medical services to remote areas. Another advantage of telemedicine is its sustainable use of resources: it can assess the condition of a patient without actually visiting him or her [ Singh R. et al., 2009: 126].

Telemedicine is the delivery of remote healthcare services to regions where the physical presence of healthcare professionals is not manageable. Such remote healthcare or telemedical services are provided to patients via information and communication technologies. This facilitates in lasting education of health care providers and thus contributes to progress in citizens' health and hence in society.

Telemedicine can be defined as the remote delivery of healthcare services through the transfer of audio, video and graphical information about a patient's health via telecommunication networks. Such information enables the healthcare provider to deliver remote consultative and diagnostic services, including planning, coordination, collaboration and education [Meher S.K. et al., 2014: 262].

Affordability and accessibility are the biggest advantages of telemedicine. It helps patients to receive fast and timely access to appropriate interventions

though both involve the application of electronic information and communication technologies to healthcare, telemedicine specifically implies long-distance patient care. (See: A. Darkins. Telemedicine and Telehealth: Principles, Policies, Performances and Pitfalls. N.Y., 2000). 
and medical services which would not generally be available otherwise. India is a huge country with large geographical distances and limited healthcare resources, which makes the provision of in-person healthcare a big challenge. Thus, telemedicine is emerging as a major boon to the rural population with its very limited spending power and access to medical services.

Telemedicine helps to save resources by facilitating remote consultations, remote routine check-ups and remote prolonged continuous monitoring. This saves patients' time and money as well as reducing the burden on secondary hospitals. Further, in times of emergency such as pandemics, telemedicine protects patients and health workers from the risk of contagious infection by making physical meetings superfluous.

Telemedicine provides patients with technologies that help them to manage their medication routines easily and efficiently, leading to the better management of disease.

In recent times, different studies have been conducted on the impact of telemedicine. One study [Daly H.L., 2000: 75] has shown that telemedicine reduces healthcare expenses for patients, making healthcare services more accessible. Furthermore, examined telemedical services accorded to patients by the All India Institute of Medical Sciences (AIIMS, New Delhi), concluding that telemedicine saves time and money and is beneficial for patients from rural areas, although the perspective profits of telemedicine and ICT have not been calculated so far.

\section{Telemedicine: methodology and legal issues}

\subsection{Telemedicine: the technology}

Just as any paradigm shift, telemedicine creates both opportunities and challenges. In its literal sense, telemedicine refers to the use of technologies to provide healthcare services to patients. When distance and remoteness are issues for the proper delivery of services, information technologies are used to allow patients to consult doctors for diagnosis and treatment. Telemedicine brings together medicine and technology, using telecommunication technologies to deliver medical services [Daar J.F., Koerner S., 1997: 18]. There are two basic classes of interactive platforms available in telemedicine [Ateriya N. et al., 2018:215]:

a) Store-and-transfer (non-synchronous consultations)/store-and-forward technologies allow images to be scanned, stored, and later forwarded anywhere in the world, eliminating distance barriers 
b) Human-human "real-time interaction" video conferencing (synchronous consultation) enables one-to-one consultations through the "virtual interaction" of practitioners and patients.

In telemedicine, real-time interactions can take place at the doctorpatient, doctor-doctor and/or doctor-paramedic levels. These interactions can be either telecenter-based or home-based. Here, synchronization between the central and peripheral nodes is the most important factor for the real-time interaction of individual participants.

In store-and-transfer, data is collected, saved and then conveyed from remote peripheral centers to the central node where it is examined by a specialist. For example, ECG (tele-cardiology), X-ray (tele-radiology) and similar data can be collected from the patient, stored and then transferred to the specialist for consultation. Non-synchronous consultations are specifically useful in cases which require monitoring the growth of a persistent and chronic disease such as detecting retinopathy in a diabetic patient.

By virtue of telemedicine, people in need of medical consultation, regardless of their location, can connect with healthcare professionals and receive access to healthcare. Telemedicine makes it possible to perform rapid medical intervention and support on-site, instead of conveying the patient to an alternative setting. Geographic remoteness no longer implies separation from therapeutic care. Thanks to technology, medical practitioners are able to deliver "audio, visual, and other data-sharing communications" to assist patients, reducing healthcare costs, broadening access to primary and specialty care, and providing the medical sector with an expanding market base. As a result, countries need neither to establish large health centers nor to train medical practitioners, but only to cultivate expertise and make use of technologies.

\subsection{IoT and cloud services for telemedicine health practices}

IoT, or Internet of Things, refers to the expansion of the capacity of the Internet beyond computers and smartphones. It has led to the creation of integrated systems comprising the Internet and digital machines. It has also engendered amalgamated digital devices with special identifiers that can be used across multiple industries.

IoT has brought about a major revolution in the domain of healthcare through the provision of continuous health monitoring services. Patients no longer need to depend solely on hospital visits for healthcare and may opt for remote medical consultation and treatment instead. Physicians can use IoT 
for continuously monitoring the progress of their patients' health. Patients can take care of their health while staying at home with the assistance of advanced gadgets such as voice-activated smart speakers or order medicine through devices such as ALEXA, saving travel time and visits to the hospital.

IoT is becoming an increasingly important part of our daily lives. It is proving to be vital in the supervision of various health and medical needs. With the advent of highly popular devices such as tablets and smartphones, the medical Internet of Things (mIoT), which combines the notions of telemedicine and telehealth, is progressively gaining acceptance. These devices in combination with Internet accessibility are making advanced services available. This results in an enrichment of user knowledge and experience. Medical staff can also make more informed choices and take quicker decisions. With Internet availability, data sharing on a cloud system has also become possible. This allows multiple users, physically and geographically distant from one another, to have access to data and information anytime, anywhere.

\subsection{Laws pertaining to telemedicine in India}

In India, the laws pertaining to telemedicine may be categorized as in Tables 1 and 2.

Table 1

\section{Laws pertaining to medical facilities and professions}

\begin{tabular}{|l|}
\hline Law \\
\hline Drugs and Cosmetics Act, 1940, and Drugs and Cosmetics Rules, $1945^{10}$ \\
\hline Indian Medical Council Act, $1956^{11}$ \\
\hline $\begin{array}{l}\text { Indian Medical Council (Professional Conduct, Etiquette and Ethics) } \\
\text { Regulations, } 2002^{12}\end{array}$ \\
\hline Clinical Establishments (Registration and Regulation) Act, $2010^{13}$ \\
\hline
\end{tabular}

${ }_{10}$ Drugs and Cosmetics Act. 1940. Drugs and Cosmetics Rules. 1945. Available at: www.cdsco.nic.in/writereaddata/2016Drugs\%20and\%20Cosmetics\% 20Act\%201940\%20 \&\%20Rules\%201945.pdf.

${ }^{11}$ Indian Medical Council Act. 1956. Available at: www.mciindia.org/documents/ theIndianMedicalCouncilActs/Complete-Act-1.pdf.

${ }^{12}$ Clinical Establishments (Registration and Regulation) Act 2010. Available at: www. clinicalestablishments.nic.in/WriteReadData/969.pdf.

${ }^{13}$ Information Technology Act. (2000). Available at: www.lawmin.nic.in/ld/P-ACT/ 2000/The\%20Information\%20Technology\%20Act\%202000.pdf. 
Information technology services are the sources used to provide telemedicine.

Table 2

\section{Laws pertaining to information technologies}

\begin{tabular}{|l|}
\hline Law \\
\hline Information Technology Act, 2000 (IT Act) \\
\hline $\begin{array}{l}\text { Information Technology (Reasonable Security Practices and Procedures } \\
\text { and Sensitive Personal Data or Information) Rules, } 2011^{15}\end{array}$ \\
\hline Information Technology Rules (Intermediary Guidelines), $2011^{16}$ \\
\hline Unsolicited Commercial Communications Regulations, $2007^{17}$ \\
\hline $\begin{array}{l}\text { Telecom Commercial Communication Customer Preference Regulations, } \\
2010 \text { [White-Williams C., Oetjen D., 2015: 4-16] }\end{array}$ \\
\hline
\end{tabular}

\section{Ethical issues of telemedicine}

Advances in ICT have resulted in the growing use of telemedicine in the treatment of diseases and patient care. With such advances, it is important to pay attention to the associated ethical issues as well. Thus, in order to ensure the confidentiality and safety of patient data and identify inefficiencies in the process, there exists a requirement to monitor cases of inefficiency of therapists so as to improve the quality of healthcare services. This also highlights the significance of ethical issues in telemedicine [Dombo E.A., Kays L., Weller K., 2014: 99].

The World Health Organization (WHO) defines telemedicine as an online healthcare service in which the geographical distance between the patient and the service provider matters. Furthermore, the ethical issues of telemedicine include the consideration of the benefits or losses incurred by patients in receiving telemedical services and their right to select therapy and take action against dissatisfactory services [Tarzian A. J., 2013: 3-13].

${ }^{14}$ Information Technology (Reasonable Security Practices and Procedures and Sensitive Personal Data or Information) Rules. 2011. Available at: www.meity.gov.in/ sites/upload_files/dit/files/GSR313E_10511(1).pdf.

15 Information Technology (Intermediaries Guidelines) Rules. 2011. Available at: www. meity.gov.in/writereaddata/files/GSR314E_10511\%281\%29_0.pdf.

${ }^{16}$ Unsolicited Commercial Communications Regulations. 2007. Available at: www. trai.gov.in/sites/default/files/201204190608149960110Regulation5june07.pdf.

17 Telecom Commercial Communication Customer Preference Regulations. 2010. Available at: www.nccptrai.gov.in/nccpregistry/regulation1diccndiv.pdf. 
The consideration of ethical issues related to telemedical services began in the 1980s. In 2006, WHO officially commissioned the American Society for Bioethics and Humanities (ASBH) to investigate ethical issues in telemedicine. The fundamental requirement was health-related knowledge and skills [Dombo E.A., Kays L., Weller K., 2014: 111]. In addition, guidelines for telemedicine were developed to streamline the process further. These guidelines facilitated the proper management of telemedical services and the assurance of their stability, regularity and safety. These guidelines aim to improve the quality of telemedical services.

Today, the Internet is used by $87 \%$ of adults. The rate of receiving online health-related information has increased by $72 \%$. This has enhanced the role of ethical issues in telemedicine, pushing stakeholders to improve the quality of healthcare services [Parsons T. D., 2016: 99-101]. This is further compounded by the fact that the use of technologies such as Internet, email, and smartphones creates a number of ethical issues in telemedicine [Langarizadeh M. et al., 2017: 351]. For example, ethical rules and regulations are required to ensure the confidentiality of patient information. In [Agarwal N. et al., 2020: 90], the author reviews and classifies the available literature on ethical issues in telemedicine.

\section{Role of telemedicine in disasters and pandemics}

Pandemics and disasters hamper the trials in giving healthcare. It is not guaranteed that telemedicine can successfully work at all times. It can be suitable in situations when medical practitioners are capable of managing and evaluating their patients. In telemedicine, visits and consultations can be booked without the staff coming in contact with viruses/infections at a time of epidemic upsurge. Telemedicine also eliminates the risk of being exposed to other communicable diseases for all patients and medical practitioners. The exposure of healthcare workers can be avoided through the use of telemedicine to screen patients remotely. Telemedicine can also improve the accessibility of medical practitioners in remote areas. Hence, during the current COVID-19 pandemic, health systems with advanced telemedicine systems are able to ensure that patients infected by the virus can quickly get the care they need. A recent paper on telemedicine [Mishra S.K., Singh I.P., Chand R.D., 2012: 151-163] studies the role played by telemedicine in the ongoing COVID-19 situation in India. Focusing on the Telemedicine Guidelines of March 2020 of the Medical Council of India, the researchers discuss the role of telemedicine in fighting the pandemic. The work significant to telemedicine and its applications are studied and summarized. 
Telehealth is appropriate for situations where medical practitioners are available to consult patients remotely. State licensing, payment and regulatory structures, program implementation, credentialing across hospitals, etc. all take time to implement, but systems with advanced telemedicine systems are in a good position to guarantee that Covid-19 patients obtain the care they need. Thus, in the present scenario, the use of telemedicine may be the most appropriate solution.

\section{Policy-based analysis}

The government is striving to incorporate telemedicine into the country's healthcare system and make it an integral part of the latter. The Department of Information Technology has laid the foundations by creating guidelines to guarantee the inter-operability [LeRouge C., Garfield M.J., 2013: 6472-6484] of telemedicine as a standard practice. A comprehensive regulatory framework should be developed to understand several diverse significant pointers which would help stakeholders to understand their roles and responsibilities in a better way. With the help of telemedicine, healthcare services can be easily delivered to different places. However, the increasing application of telemedicine can also lead to the emergence of different legal and ethical issues [Balarajan Y., Selvaraj S., Subramanian S.V., 2011: 505-515]. It should be obligatory for the main parties involved, including patients and doctors, to have a clear and precise understanding of their rights. Their role expectations and duties in this new framework should also be well defined. For example, the risks of using telemedicine include the exposure of patients' confidential information such as financial and medical data. Stringent rules should be elaborated to make discretion compulsory so as to reduce concerns about the exposure of private information. Furthermore, patients can use telemedicine to receive treatment from several healthcare practitioners residing in different places, evoking controversy about liability for the patient's treatment. This can result in doctors and health workers being unclear and hesitant about their responsibilities, obligations and legal duties.

The solid financial benefits of telemedicine from the patient's viewpoint include saving travel time and money by receiving treatment at home. However, the ROIs from the healthcare provider's perspective are unspecified and uncertain. Hence, many telemedicine initiatives are implemented as "concept projects" by state enterprises or as public private partnerships (PPP). These enterprises are mainly dependent on government funding for money and hence do not strive for financial viability. By portraying 
telemedicine as a vital part of the healthcare environment and endorsing the vigorous involvement of the private sector, many policy initiatives play a key role in making telemedicine projects financially viable. This is explicitly authoritative as healthcare is generally delivered by private businesses or hospitals across India [Dasgupta A., Deb S., 2008: 3-8].

\section{Literature review}

Table 3

Literature Review of Previous Studies in Telemedicine

\begin{tabular}{|c|c|}
\hline Title of publication & Type, Description \\
\hline $\begin{array}{l}\text { "Telemedicine: A new } \\
\text { horizon in public health } \\
\text { in India" [Ganapathy K., } \\
\text { Ravindra A., 2009: 576-585] }\end{array}$ & Review \\
\hline $\begin{array}{l}\text { "Telemedicine in India: } \\
\text { The Apollo story." } \\
\text { [Bhaskaranarayana A., } \\
\text { Satyamurthy L.S., Remilla } \\
\text { M.L., 2009: 586-591] }\end{array}$ & $\begin{array}{l}\text { Review, discusses the role of ATNF (Apollo } \\
\text { Telemedicine Networking Foundation) } \\
\text { in the growth and development of } \\
\text { telemedicine in South Asia. }\end{array}$ \\
\hline $\begin{array}{l}\text { "Telemedicine in India: } \\
\text { Current scenario and the } \\
\text { future" [Bagchi S., 2006: 82] }\end{array}$ & $\begin{array}{l}\text { This paper discusses the role played by } \\
\text { the Indian Space Research Organization, } \\
\text { numerous government agencies, } \\
\text { Department of Information Technology } \\
\text { and Ministry of Health \& Family Welfare } \\
\text { (MOH\&FW), state governments, and } \\
\text { leading medical and technical institutions } \\
\text { of India in the deployment of telemedicine } \\
\text { initiatives throughout the country }\end{array}$ \\
\hline $\begin{array}{l}\text { "Indian Space Research } \\
\text { Organization and } \\
\text { telemedicine in India" } \\
\text { [Ganapathy K., 2002: 388- } \\
\text { 394] }\end{array}$ & $\begin{array}{l}\text { This article discusses the role played by } \\
\text { ISRO in the enactment of various measures } \\
\text { required for the deployment of telemedicine } \\
\text { initiatives in India. It examines the ISRO's } \\
\text { approach, the various stakeholders involved } \\
\text { at different levels, and future prospects. }\end{array}$ \\
\hline $\begin{array}{l}\text { "Telemedicine and } \\
\text { neurosciences in developing } \\
\text { countries" [Sood S.P. et al., } \\
\text { 2007: 257-268] }\end{array}$ & $\begin{array}{l}\text { Telemedicine and neurosciences: } \\
\text { the numerous implications of developing } \\
\text { technologies for providing neurosurgical } \\
\text { care to rural and urban areas of India as well } \\
\text { as other countries. }\end{array}$ \\
\hline
\end{tabular}




\begin{tabular}{|c|c|}
\hline Title of publication & Type, Description \\
\hline $\begin{array}{l}\text { "Differences in public and } \\
\text { private sector adoption of } \\
\text { telemedicine: Indian case } \\
\text { study for sectoral adoption" } \\
\text { [Brindha G., 2013: sup. 5] }\end{array}$ & $\begin{array}{l}\text { Differences in the adoption of telemedicine } \\
\text { by the public and the private sectors in India }\end{array}$ \\
\hline $\begin{array}{l}\text { "Emerging trends of } \\
\text { telemedicine in India" [Pal } \\
\text { A. et al., 2005: 59-65] }\end{array}$ & $\begin{array}{l}\text { Discusses the demand, challenges, } \\
\text { and procedures of telemedicine }\end{array}$ \\
\hline $\begin{array}{l}\text { Telemedicine diffusion } \\
\text { in a developing country: } \\
\text { The case of India (March } \\
\text { 2004) [Chandwani R.K., } \\
\text { Dwivedi Y.K., 2015: 393-400] }\end{array}$ & $\begin{array}{l}\text { Potential of telemedicine development } \\
\text { and diffusion in India }\end{array}$ \\
\hline $\begin{array}{l}\text { "Telemedicine in India: } \\
\text { Current state, challenges } \\
\text { and opportunities" } \\
\text { [Chellaiyan V.G. et al., 2019: } \\
\text { 1872] }\end{array}$ & $\begin{array}{l}\text { Scope, challenges for diffusion } \\
\text { and prevailing scenario of telemedicine } \\
\text { in India }\end{array}$ \\
\hline $\begin{array}{l}\text { "Telemedicine in India: } \\
\text { Where do we stand?" } \\
\text { [Sood S.P., Tech M., 2004: } \\
\text { 29-32] }\end{array}$ & Position of Indian telemedicine initiatives \\
\hline $\begin{array}{l}\text { "Implementing telemedicine } \\
\text { technology: Lessons from } \\
\text { India" [Ghosh A., Gupta R., } \\
\text { Misra A., 2020: 273-276] }\end{array}$ & $\begin{array}{l}\text { Discussion of a pilot telemedicine scheme } \\
\text { in India. Analysis and insight into its } \\
\text { strengths and shortcomings }\end{array}$ \\
\hline $\begin{array}{l}\text { "Telemedicine for diabetes } \\
\text { care in India during the } \\
\text { COVID19 pandemic and } \\
\text { national lockdown period: } \\
\text { Guidelines for physicians, } \\
\text { diabetes \& metabolic } \\
\text { syndrome" [Sangal A.K. et al., } \\
\text { 2004: 149-151] }\end{array}$ & $\begin{array}{l}\text { The paper briefly discusses suggestions } \\
\text { and guidelines pertaining to the role } \\
\text { of telemedicine for patients with diabetes, } \\
\text { along with its utility and limitations. }\end{array}$ \\
\hline $\begin{array}{l}\text { "Communication satellite- } \\
\text { based network for } \\
\text { telemedicine in India" } \\
\text { [Ray S., Sharma P., } \\
\text { Kustwar R.K., 2017: 156-172] }\end{array}$ & $\begin{array}{l}\text { The paper discusses the application } \\
\text { of the communication satellite network } \\
\text { to telemedicine in India }\end{array}$ \\
\hline
\end{tabular}


The basic resource prerequisites for telemedicine are human capital and technological matters. To make an efficient medical information network, technologies must assure the precise transmission of information with minimal losses in recording, loading and delivering information. The insufficient penetration of the Internet is a limitation that must be solved to permit the forwarding and storing of high-resolution videos. To guarantee effectiveness, the technological framework must study cost effectiveness and affordability. During the preliminary phase, it is vital to experiment with telemedicine mediations for a particular type of disease to find acceptable solutions to issues such as showing diabetic retinopathy through a fundus camera and identifying affordable versions of the technology. Such problems as consistent power supply and appropriate hardware must also be overcome to confirm technology dependability. Indian doctors are considerably burdened with patients, which is confirmed by the low doctor to population ratio. Involving doctors in healthcare delivery through telemedicine requires overt methods for making tele-consultation operative and efficient. Additionally, paramedical staff provides the connection between doctors residing in cities and patients in villages. To reduce the shortage of healthcare personnel and increase the number of employees who are familiar with telemedicine, telemedicine training must be offered. It is key to improving the telemedicine coverage of the village population.

Telemedicine mediations are limited to a particular structure of medicine. The community has to be included in the delivery flowchart process as it is the most important component to increase the tolerability of telemedicine. ASHA (Accredited Social Health Activist) played an important role in the plan of NRHM (National Rural Health Mission) by endorsing the connection between the community and the formal health framework. Disabling the sociocultural obstacles and adopting telemedicine in rural areas may well depend on the use of telemedicine in the first stage of treatment such as primary care. The use of telemedicine in primary care has been insufficient so far. To use telemedicine in primary care, one needs to take a bottom-up approach starting from the rural population, considering their requirements, understanding the socio-technical framework for deploying telemedicine and involving native thought leaders. Moreover, the strategy and processes should be based on information sharing, framework practicability and the needs of villagers.

\section{Applications of telemedicine}

\subsection{Telehealth}

Telehealth is used for endorsing and providing healthcare services across large distances. It can be classified into tele-consultation and telefollow-up. 
Telehealth offers many ways of delivery, including "video consultation, transferring reports and images, creating portals for patients (e-health), monitoring vital signs, frequent medical instruction, consumer-focused wireless frameworks and nursing call-centers," text messaging, e-mail, surgical training and remote data capture.

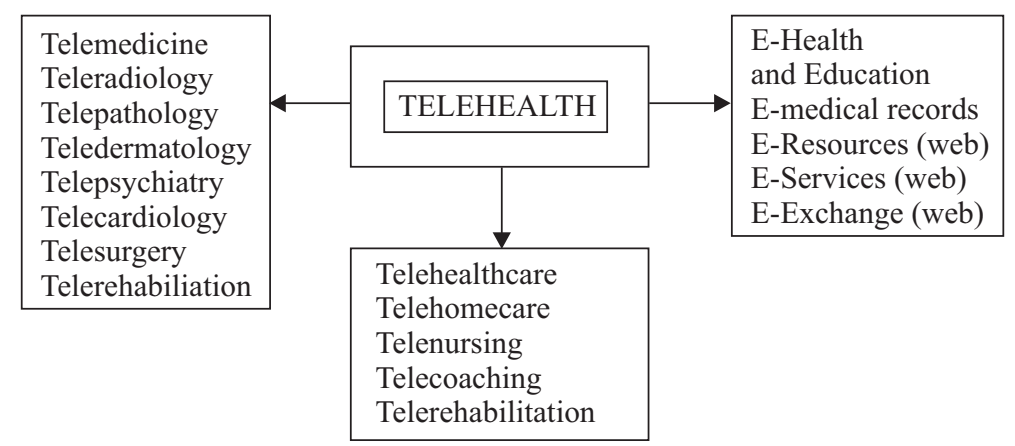

Figure 2. Telehealth flow chart

Source: http://newtel.vn/en/difference-between-telemedicine-and-telehealth/

\subsection{Tele-education}

Tele-education can be defined as the process of providing distance education, whether regulated or unregulated, via ICT for a flexible, interactive and accessible learning experience for the student. Telemedicine and ehealthcare services have been used competently and considerately to deal with the consequences of natural and manmade tragedies and disasters. Many studies have shown the effectiveness of telemedicine in dealing with disasters, especially in remote areas marked by a shortage of doctors and other healthcare services.

\subsection{Tele home healthcare}

Telemedicine technologies are vital for providing healthcare at home for patients who are aged or underserved, cannot leave their homes or have chronic illnesses. It allows healthcare specialists to observe patients from a distant central station. Distant home-based monitoring of patients is efficient, rapid, inexpensive and time-saving. Virtual interactions in telehealth home care improve the quality of home healthcare at a lower cost, increase patient satisfaction, and expand the access of healthcare professionals and patients to more sophisticated and expensive types of care. The vital functions of patients may be observed whenever required through ICT. 


\section{Challenges of telemedicine}

In India, the biggest challenge to tackle at the policy level is to promote telemedicine and turn it into an essential component of the healthcare delivery system. [LeRouge C., Garfield M. J., 2013: 6472-6484] discusses some initiatives taken at the policy level such as the participation of Department of Information Technology (DIT) in the process of creating guidelines for the regularization of the telemedicine infrastructure to assure the operation of telemedicine at different levels. In addition, attention must be paid to many other important aspects of telemedicine. This should require the elaboration of a complete governing framework that will allow stakeholders to understand their responsibilities and liabilities.

As the operation of telemedicine increases and it is applied across varied geographies to deliver healthcare and share essential medical information, numerous new legal and ethical issues arise. For the proper use and implementation of telemedicine, the chief stakeholders, i.e., patients and doctors, will have to understand their role, duties and rights in the utilization of telemedicine. For example, if used improperly, telemedicine has the potential to threaten the confidentiality and secrecy of critical medical and economic information of patients. Thus, specific guidelines are required for assuring adequate provisions for the preservation of the confidentiality of patient data to reduce patient concerns.

Another scenario that can affect stakeholders is the treatment of a single patient by several doctors and healthcare professionals across multiple geographies, which can cause a conflict of ownership and accountability for the patient's treatment plan. Under such circumstances, doctors and health workers can be uncertain of their lawful accountability. According to some authors [Andriola M., 2019: 13] the number of legal suits against medical practitioners and doctors is increasing. Therefore, policy makers should elaborate guidelines and policies that facilitate the incorporation of telemedicine into the bigger healthcare delivery system.

As far as the economic advantages of telemedicine are concerned, patients are definitely receiving benefits such as saving on costs for travelling to urban areas for treatment. On the other hand, the returns on the investments of healthcare providers are highly uncertain. As a result, the government is organizing telemedicine interventions as "concept projects" or PPPs [LeRouge C., Garfield M. J., 2013: 6472]. Telemedicine projects normally receive government grants, as a result of which little consideration is paid to their financial viability. 
For telemedicine to become an integral part of the Indian healthcare sector and for the active participation of the private sector in telemedicine, several policy initiatives must be taken. Such initiatives should be financially feasible. Furthermore, the active participation of the private sector in telemedicine is required, as the private sector plays the leading role in healthcare delivery across rural and urban areas [Dasgupta A., Deb S., 2008: 3-8].

The two basic resources required for telemedicine are people and technologies. For telemedicine to emerge as an operational technology in the field of healthcare, it must operate in an error-free manner, assuring negligible losses during the collection, storage and transfer of information. The availability of network infrastructure should be properly managed, as it is one of the major challenges in the field of telemedicine according to [LeRouge C., Garfield M. J., 2013: 6484]. This is due to the fact that good broadband connections are required for managing the demand for video and store-and-forward services. In addition, technologies should be designed to assure cost-efficiency and affordability.

While telemedicine is still at the pilot stage, it should be applied to a specific disease so as to test solutions and assess minor problems before being used for a wide range of diseases in a cost-effective manner. For example, the fundus camera can be used both for diabetic retinopathy and for image-based diagnoses of many illnesses of the teeth, skin, etc. Such an approach can share expenses between several specialties and improve the cost effectiveness of the technology. It is also important to focus on the challenges of reliable power supplies and suitable hardware.

India is experiencing a huge shortage of doctors, making existing specialists overloaded with work. Telemedicine can provide an effective solution to this problem. However, it needs explicit strategies to be workable. The emphasis on explicit diseases can significantly limit the scope of judgmental problem-solving and decision-making among doctors, greatly reducing their workload.

Telemedicine can also overcome the widespread shortage of paramedical personnel and the deficiency of staff training, which shows the importance of extending telemedicine to villages.

The predominant recognized norms that regulate the healthcare consumption of the population can be ascribed to socio-cultural barriers. In the case of primary care in the context of developing countries, alternative systems of medicine provided by native doctors are the typical choice available to patients. However, telemedicine is constrained to the official 
system of medicine. In order to increase the adoption level of an intervention, it is important to involve the community in the process of healthcare delivery, which is an important design element for acceptability. In the same direction, ASHA (Accredited Social Health Activist) has acted as the backbone of the design of the NRHM program by safeguarding the relation between the formal health system and the community.

The integration of telemedicine into primary healthcare should play the biggest role in reducing socio-cultural barriers in rural areas to enhance telemedicine adoption. The initiative of telemedicine discussed in the previous sections has mostly focused on the delivery of expert advice from the central nodes to the periphery. This has subsequently contributed to secondary and tertiary healthcare delivery as well. As far as the design of technology, processes and systems is concerned, a "top-down" method is used. While telemedicine has a huge potential in the healthcare industry, it is unfortunately underutilized today.

In contrast, telemedicine for primary care requires a "bottom-up" method. This can be initiated at the community level by measuring the requirements of the community, the participation of local thought leaders, etc. Furthermore, the implementation of a bottom-up approach in telemedicine will promote efficiency and a higher adoption rate at the secondary and tertiary levels as well. One should design technologies, systems and processes for primary-care telemedicine only after understanding the predominant socio-technical systems in communities.

\section{Conclusion}

The Indian government is dedicated to providing equal and non-discriminatory access to high-quality healthcare to all citizens. The inclusivity of the health system can be improved with the help of digital health. Thus, turning telemedicine into a routine method of the healthcare system will reduce unfairness and hurdles to healthcare access, despite all the hesitations voiced about the new technology.

Early telemedicine ventures in the country were backed by government funding. Such ventures were either introduced into the public health framework or implemented as PPPs. Telemedicine needs the vigorous participation of private companies on a continual basis to become an essential part of the healthcare framework in the country. This requires the involvement of all the participants, including policymakers, doctors, specialists, paramedical staff, coordinating and technical staff, and the rural community from the initial planning stage on. 
Telemedicine leads to an overall decrease in healthcare costs by assuring the fast delivery of healthcare at a minimal price. As technology develops to enable quicker and more effective communication, the logistical hurdles that once hindered the diffusion of telemedicine will disappear. Nevertheless, the legal system must also catch up with the process.

Telemedicine encroaches upon the conventional legal framework in three ways: (a) in the regulation of medical practice, (b) in dispute resolution of negligence cases and (c) in the lack of legal safeguards for the confidentiality of patient information. The downsides of telemedicine are the lack of a standardized arrangement for interaction. The Medical Council of India (MCI) was created by the Indian Medical Council Act in 1956. In 2019, the National Medical Commission Act replaced the MCI by the National Medical Commission (NMC). Other than the NMC, there exist the Indian Nursing Council, the Dental Council of India, the Rehabilitation Council of India and the Pharmacy Council of India. The NMC Act sets out the regulatory and advisory role of the NMC and the Medical Advisory Council under the aegis of the Ministry of Health and Family Welfare (MoHFW). Through this Act, the Ministry not only frames strategies for regulating medical institutions and medical professionals but also maintains minimum standards for medical education. Furthermore, medical devices are governed in India by the Drugs and Cosmetics Act (1940) along with the Medical Device Rules (2017), which cover a wide range of drugs, therapeutic substances, diagnostics and medical devices. The Central Drug Standards Control Organization (CDSCO) serves as a regulatory body for pharmaceuticals and medical devices. These regulatory frameworks are consistent with pertinent technical recommendations from WHO. Although MoHFW issued the Telemedicine Practice Guidelines as Appendix 5 to the Indian Medical Council (Professional Conduct, Etiquette and Ethics) Regulations (2002) in tandem with NITI Aayog (National Institution for Transforming India), there still remain lot of loopholes. These are mere guidelines that lack enforceability. The notorious 2018 Mumbai High Court judgment in Deepa Sanjeev Pawaskar v. State of Maharashtra highlighted the perils of telemedical practice by ruling that a medical practitioner was guilty of medical negligence under Section 304A of IPC by causing death due to negligence. ${ }^{18} \mathrm{In}$ the conventional approach, medical negligence can be established by proving the existence of the following elements: a duty to be performed by a medical practitioner in conformity with certain standards; a breach of these standards of care; (3) an

${ }^{18}$ See SCC OnLine Bom 1841 Order of 25 July 2018. 
injury; and (4) a causal relationship between the breach of care and the patient's injury. However, when the judgment states "prescription without physical diagnosis and henceforth resulting in the death of the patient amounts to criminal negligence on the part of the doctors," ${ }^{19}$ the question pertains to telemedicine. What checklists can assure a reasonable degree of care and skill? As telemedicine makes use of technical means, what precautions can be taken by doctors and patients against errors taking place due to a breakdown in communication because of technical glitches? These and other questions are ambiguous. In other countries, the term "telemedicine entity" is properly defined so as to set down the liability of stakeholders who provide telemedical services. ${ }^{20}$ Conventional structures should be contrasted with telemedicine's ability to provide diagnoses for inaccessible patients in India.

Moreover, the guidelines state that only doctors enrolled in the State Medical Register or the Indian Medical Register can practice medicine. ${ }^{21}$ However, there is no mention of any authority who crosschecks the names of medical practitioners in telemedical services. Conversely, how can a medical practitioner be sure of the patient's identity and his or her medical history when entering into a virtual office via video-conferencing? Licensing as a regulatory element serves the vital objective of guaranteeing that medical practitioners meet educational and clinical capability criteria. This helps to safeguard the public from incompetent or unskilled practitioners. Licensing is significant for enforcing medical standards, as the licenses of unfit practitioners can be withdrawn. However, the incoherent telemedicine system currently prevailing in India prevents the distribution of information amid licensing authorities. There is no checklist for verifying whether a practitioner of telemedicine is licensed or whether his license has been suspended or revoked.

Let us consider a recent case regarding a prescription that was shared by many users in the social media. The prescription was entitled "On fighting coronavirus as per Indian Council of Medical Research (ICMR) guidelines" and posted by a certain "Dr Raj Kamal Agarwal, Senior Consultant at the Department of Anesthesiology of Sir Ganga Ram Hospital, New Delhi." It recommended taking "HCQ, $400 \mathrm{mg}$ " once a week along with vitamin C

${ }^{19}$ Ibid. Para 7.

${ }^{20}$ See the Electronic Code of Federal Regulations (e-CFR) - the web version of the Code of Federal Regulations (CFR) published in the Federal Register by the departments and agencies of the US Federal Government.

${ }^{21}$ See the Gazette Notification for Telemedicine Practice Guidelines. Available at: https://www.mohfw.gov.in/pdf/Telemedicine.pdf. (accessed: 15.11.2020) 
to gain immunity against the pandemic. This matter came to the attention of Ganga Ram Hospital officials, who filed a mal-information case. On due verification, it was found that the ICMR had never issued such a guideline for taking HCQ pills. If such prescriptions can make rounds during the pandemic, what can happen with the audio or video clips that are regularly used on telemedical services? This again poses the question of introducing safeguards into current regulations.

Another concern pertains to "informed consent," which is a vital prerequisite for treating a patient in medico-legal jurisprudence. Essential communication between patients and medical practitioners in the course of medical treatment is fundamentally embodied in the legal dogma of "informed consent." In accordance with professional standards, there exists the practice of direct diagnosis, in which medical practitioners converse personally with patients to gain the necessary information. The patient's consent should go hand in hand with the trust he or she places in the medical practitioner's respect of the confidentiality of their dialogue [Wibberley L.E. , 2017:885]. In telemedicine, the biggest accountability concerns relate to the establishment of the physician-patient relation, the applicable standard of care, and informed consent. With no clear explanation provided in the MoHFW Telemedicine Practice Guidelines and no case precedents, it remains uncertain whether the confidentiality standards used in face-to-face consultations remain suitable within the telemedicine setting, particularly in view of the advanced technologies involved. There are many researchers who opine that the new technologies risk depriving medical professionals of information that they would obtain during an in-person check-up and possibly lead to mistreatment [Lee T. H., 2010: 69]. Such risks may affect every stage of medical care, including examination, diagnosis and treatment. The legal doctrine of care in negligence cases is the "reasonable person standard test" - i.e., what a reasonable person would do if he faces the same set of circumstances as the defendant. ${ }^{22}$ Given that telemedical services considerably alter traditional face-to-face consultations, one must examine whether the rules for proving the standard of care should be changed. Another issue that needs to be resolved regards the "vicarious liability" principle under the Common Law. Civil law recognizes the liability of the employer for an employee who makes errors in the course of his/her employment. The question remains open whether a hospital is responsible for telemedical care provided by a practitioner associated with the institution [Stanberry B., 2006: 175].

${ }^{22}$ Jacob Mathew vs. State of Punjab \& Anr. (2005) 6 SCC 1 


\section{Future directions}

As an innovative model for processing medical data, telemedicine is governed by different legal frameworks dealing with medical regulation, data protection, data sharing, communication technologies and further aspects of scientific research. Hence it involves aspects of cyber law, especially under the Information Technology (Reasonable Security Practices and Procedures and Sensitive Personal Data or Information) Rules (2011), the Information Technology (Intermediaries Guidelines) Rules (2011), the Telecom Unsolicited Commercial Communications Regulations (2007) and the Telecom Commercial Communication Customer Preference Regulations (2010). However, issues such as the leakage of patient data to third parties, the mode of storing such data, subsequent detrimental effects on data, etc. are not mentioned in the MoHFW governmental guidelines. Such administrative aspects of telemedical services are very important, because they entail elements related to transmitting and storing session footage and patient data, maintaining and updating software, capacity building, infrastructure, and training programs for healthcare workers and technicians.

In addition, it is important to understand the roles of different stakeholders of this service. These stakeholders include not only patients and doctors but also telemedicine technicians, paramedical service providers, teleservice providers, the pharma industry and insurance companies. The principal issue pertains to the protection of patient privacy with the digitization of medical records. In the telemedicine scenario, providers must meet the challenge of guaranteeing the adequate protection of the privacy of audio and video communications. Data privacy in healthcare must strike a balance between utility and security. MoHFW guidelines do not identify the party that should ultimately be held for a security breach. Telemedicine involves a continual interchange of information among the patient and the service provider. The personal information of patients, be it their medical history or physical disorders or physiological conditions, have to be categorized as sensitive personal data in order to give patients an opportunity for legal recourse. With the Personal Data Protection Bill (2019) pending before parliament, safeguarding patients' data is a challenge that India needs to overcome. The potential use of cryptography, password-protected attachments, etc. has been proposed by jurists in other countries to assure information privacy.

Because telemedicine is a relatively new field that is indispensable during the current pandemic, patients need to gain a proper understanding of its advantages and disadvantages. As a result, the elaboration of its frame- 
work should receive priority attention. In the absence of personal data protection legislation in India today, guidelines for telemedicine, including its clinical, technical and operational aspects, need to be drafted and then approved by the National Medical Commission (NMC). What are the limitations of telemedical services? What are its dos and don'ts? What happens if one or more avenues of communication/examination are lost? Where shall the patient's records be kept? These and other questions can be answered only through the development of an NMC framework that would regulate all telemedicine consultations.

\section{D国 References}

1. Achary R.V., Rai J.J. (2016) Evaluation of patient and doctor perception toward the use of telemedicine in Apollo Tele Healthcare services, India. Journal of Family Medicine and Primary Care, no 5, pp. 798-803. https://doi.org/10.4103/2249-4863.201174.

2. Adam T. et al. (2005) Cost effectiveness analysis of strategies for maternal and neonatal health in developing countries. BMJ, no. 331, p. 1107.

3. Agarwal N. et al. (2020) Telemedicine in India: A tool for transforming healthcare in the era of COVID-19 pandemic. Journal of Education and Health Promotion, no 9, p. 190. https://doi.org/10.4103/jehp. jehp_472_20.

4. Andriola M. (2019) Telemedicine and legal disruption. Health Law \& Policy Brief, p. 13.

5. Ajami S., Lamoochi P. (2014) Use of telemedicine in disaster and remote places. Journal of Education and Health Promotion, no 3, p. 26. https://doi.org/10.4103/2277-9531.131886.

6. Ateriya N. et al. (2018) Telemedicine and virtual consultation: The Indian perspective. The National Medical Journal of India, vol. 31, no. 4, p. 215.

7. Bagchi S. (2006) Telemedicine in rural India. PLoS Med, no. 3, p. 82.

8. Balarajan Y., Selvaraj S., Subramanian S.V. (2011) Healthcare and equity in India. The Lancet, no. 377, pp. 505-515.

9. Bhaskaranarayana A., Satyamurthy L.S., Remilla M.L. (2009) Indian Space Research Organization and telemedicine in India. Telemed $J$ E Health, no. 16, pp. 586-591. doi: 10.1089/tmj.2009.0060. PMID: 19659415.

10. Binkley F. (2003) Predicting potential of wearable technology. IEEE Eng. Med. Biol. Mag., no. 3, pp. 23-27. 
11. Boric-Lubecke O., Lubecke V.M. (2002) Wireless house calls: Using communications technology for healthcare and monitoring. IEEE Microwave Mag., no. 3, pp. 43-48.

12. Bonato P. (2003). Wearable sensors/systems and their impact on biomedical engineering. IEEE Eng. Med. Biol. Mag., no. 3, pp. 18-20.

13. Brindha G. (2013) Emerging trends of telemedicine in India. Indian Journal of Science and Technology, no. 6 (suppl. 5).

14. Chandwani R.K., Dwivedi Y. K. (2015) Telemedicine in India: Current state, challenges and opportunities. Transforming Government: People, Process and Policy, vol. 9, no. 4, pp. 393-400.

15. Chellaiyan V.G. et al. (2019) Telemedicine in India: Where do we stand? Journal of Family Medicine and Primary Care, no. 6, pp. 1872.

16. Dasgupta A., Deb S. (2008) Telemedicine: A new horizon in public health in India. Indian Journal of Community Medicine, no. 1, pp. 3-8. https://doi.org/10.4103/0970-0218.39234.

17. Daar J.F. (1995) Informed consent: Defining limits through therapeutic parameters. Whittier Law Review, vol. 16, p. 188.

18. Daly H.L. (2000) Telemedicine: The invisible legal barriers to the healthcare of the future. Annals of Health Law, no. 9, p. 75.

19. Daar J.F., Koerner S. (1997) Telemedicine: Legal and practical implications. Whittier Law Review, no. 1, p. 18.

20. Della Mea V. (2001) What is e-health: The death of telemedicine? Journal of Medical Internet Research, no. 2, pp. 1-2.

21. Dombo E.A., Kays L., Weller K. (2014) Clinical social work practice and technology: Personal, practical, regulatory, and ethical considerations for the twenty-first century. Social Work in Healthcare, no. 9, pp. 900-919.

22. Doarn C.R., Merrell R.C. (2014) Telemedicine and e-health in disaster response. Telemedicine Journal and e-Health, no. 7, pp. 605-606. https://doi.org/10.1089/tmj.2014.9983.

23. Dowling R. A. (2015) Telemedicine: Are we reaching a tipping point? Urology Times, no. 2, p. 2730.

24. Estrin D. (2010) Participatory sensing: Applications and architecture. IEEE Internet Computing, vol.14(1), pp. 12-14.

25. Ganapathy K., Ravindra A. (2009) Telemedicine in India: The Apollo story. Telemed J E Health, no. 6, pp. 576-585. doi: 10.1089/ tmj.2009.0066. PMID: 19659414.

26. Ganapathy K. (2002) Telemedicine and neurosciences in developing countries. Surg. Neurol., no. 6, pp. 388-394. doi: 10.1016/s00903019(02)00924-2. PMID: 12517618. 
27. Ganesh K. (2009) Patient-doctor relationship: Changing perspectives and medical litigation. Indian Journal of Urology, no. 3, p. 356.

28. Ghosh A., Gupta R., Misra A. (2020) Telemedicine for diabetes care in India during COVID19 pandemic and national lockdown period: Guidelines for physicians. Diabetes \& Metabolic Syndrome: Clinical Research \& Reviews, no 4, pp. 273-276. https://doi.org/10.1016/j.dsx.2020.04.001.

29. Lahariya C. et al. (2007) A critical review of national rural health mission in India. Internet J. Health, no. 1, pp.1-7.

30. Langarizadeh M. et al. (2017) Application of ethics for providing telemedical services and information technology. Medical Archives, no. 5, p. 351 .

31. LeRouge C., Garfield M.J. (2013) Crossing the telemedicine chasm: Have the US barriers to widespread adoption of telemedicine been significantly reduced? International Journal of Environmental Research and Public Health, no. 12, pp. 6472-6484.

32. Masic I. et al. (2009) Tele-education as a method of medical education. Medical Archives, no. 6, p. 350.

33. McSherry R., Pearce P. et al. (2011) Clinical governance: A guide to implementation for healthcare professionals. Oxford: Wiley-Blackwell, $182 \mathrm{p}$.

34. Meher S.K. et al. (2014) Awareness and attitudes of geriatric patients towards telemedicine in India. Gerontechnology, no. 2, p. 262.

35. Mishra S.K., Singh I.P., Chand R.D. (2012) Current status of telemedicine network in India and future perspective. Proceedings of the AsiaPacific Advanced Network, issue 32, pp. 151-163.

36. Mishra S.K., Kapoor L., Singh I.P. (2009) Telemedicine in India: Current scenario and the future. Telemedicine and e-Health, no. 6, pp. 568575. doi: 10.1089/tmj.2009.0059. PMID: 19659413

37. Neville C.W. (2018) Telehealth: A balanced look at incorporating this technology into practice. SAGE Open Nursing. https://doi. org/10.1177/2377960818786504.

38. Nishtar S. et al. (2012) Protecting the poor against health impoverishment in Pakistan: Proof of concept of the potential within innovative web and mobile phone technologies. World Health Report. Background Paper 55. Available at: 16.04.2019)http://www.rsis.edu.sg/nts/resources / db/uploadedfiles/WHR_2010_HEARTFILE.pdf. (accessed: 16.04.2019)

39. Nutakki A. et al. (2019) A review of role of telemedicine in disaster management: A pharmacist perspective. In: Rao P. et al. (eds.), Proceedings of International Conference on Remote Sensing for Disaster Management. Available at: https://doi.org/10.1007/978-3-319-77276-9_29. 
40. Parsons T.D. (2016) Telemedicine, mobile, and internet-based neurocognitive assessment. In: Clinical Neuropsychology and Technology. N.Y.: Springer, pp. 99-111.

41. Pal A. et al. (2005) Telemedicine diffusion in a developing country: The case of India. IEEE Transactions on Information Technology in Biomedicine, no 1, pp. 59-65.

42. Ray S., Sharma P., Kustwar R. K. (2017) Scope and challenges of telemedicine technology in India: Policy perspective on innovation and sustainable development. In: India S\&T Series, vol. IV, pp. 156-172.

43. Rotheram-Borus M.J., Ingram B.L. et al. (2012) Adoption of selfmanagement interventions for prevention and care. Primary Care: Clinics in Office Practice, no. 4, pp. 649-660.

44. Sangal A.K. et al. (2004) Communication satellite-based network for telemedicine in India. In: Proceedings of the 6th International Workshop on Enterprise Networking and Computing in Healthcare Industry, pp. 149-151. Odawara. doi: 10.1109/HEALTH.2004.1324503.

45. Sharma A. et al. (2013) Healthcare inequity and physician scarcity empowering non-physician healthcare. Economic \& Political Weekly, no. 13 , pp. 112-117.

46. Singh R. et al. (2009) A theory of rural telehealth innovation: A paradoxical approach. ICIS. $126 \mathrm{p}$.

47. Sood S.P., Tech M. (2004) Implementing telemedicine technology: lessons from India. World Hospitals and Healthcare Services, no. 3, pp. 29-32.

48. Sood S.P. et al. (2007) Differences in public and private sector adoption of telemedicine: Indian case study for sectoral adoption. Studies in Health Technological Information, no. 130, pp. 257-268. PMID: 17917199.

49. Stanberry B. (2006) Legal and ethical aspects of telemedicine. Journal of Telemedicine and Telecare, no. 4, p. 175.

50. Tarzian A.J. (2013) Healthcare ethics consultation: An update on core competencies and emerging standards from the American Society for Bioethics and Humanities' Core Competencies Update Task Force. The American Journal of Bioethics, no. 2, pp. 313.

51. Travis P., Bennett S. et al. (2004) Overcoming health system constraints to achieve the Millennium Development Goals. The Lancet, no. 364, pp. 900-906.

52. Turning doctors into leaders. Harvard Business Review, no. 4, p. 69.

53. Wibberley L.E. (2017) Telemedicine in Illinois: Untangling the complex legal threads. Journal Marshall Law Review, no. 50, p. 885. 
54. White-Williams C., Oetjen D. (2015) An ethical analysis of telemedicine: Implications for future research. International Journal of Telemedicine and Clinical Practices, no. 1, pp. 4-16.

The article was submitted 12.07.2021; approved after reviewing 11.10.2021; accepted for publication 01.11.2021. 